\title{
Glutamate Transporter Protein Subtypes Are Expressed Differentially during Rat CNS Development
}

\author{
Akiko Furuta, ${ }^{1}$ Jeffrey D. Rothstein, ${ }^{1,2}$ and Lee J. Martin ${ }^{2,3}$ \\ Departments of ${ }^{1}$ Neurology, ${ }^{2}$ Neuroscience, and ${ }^{3 P}$ athology, Division of Neuropathology, Johns Hopkins University \\ School of Medicine, Baltimore, Maryland 21287
}

\begin{abstract}
Extracellular glutamate concentrations are regulated by glial and neuronal transporter proteins. Four glutamate transporter subtypes have been identified in rat brain; GLAST and GLT-1 are primarily astrocytic, whereas EAAC1 and EAAT4 are neuronal. Using immunoblotting and immunohistochemistry with subtype-specific antipeptide antibodies, we examined the protein expression and regional and cellular localization of each glutamate transporter subtype in embryonic and postnatal rat CNS. Each transporter had a specific pattern of expression. GLAST immunoreactivity was low prenatally but became enriched in cerebellar Bergmann glia early postnatally and then was also present in forebrain later postnatally. The posttranslational modification of GLAST was unique among the subtypes; glycosylated GLAST increased with maturation, whereas nonglycosylated protein decreased in abundance postnatally. GLT-1 was present in fetal brain and spinal cord,
\end{abstract}

with expression progressively increasing to adult levels throughout the neuraxis by postnatal day 26. Transient expression of GLT-1 immunoreactivity along axonal pathways was observed prenatally, in contrast to the exclusive localization of GLT-1 to astrocytes in the adult CNS. EAAC1, localized to neurons, was enriched in forebrain, diencephalon, and hindbrain during prenatal and postnatal development. EAAC1 expression was greater in newborn brain compared with adult brain. EAAT4 had a region-specific distribution; EAAT4 was mainly in cerebellum, localized to Purkinje cells, with much lower levels in forebrain. EAAT4 levels increased in cerebellum with age. We conclude that during CNS development the expression of glutamate transporter subtypes is differentially regulated, regionally segregated, and coordinated.

Key words: brain development; excitatory amino acid; perinatal brain damage; corticogenesis; excitotoxicity; striatum
Glutamate is the major excitatory neurotransmitter in the mammalian CNS (Fonnum, 1984) and may also have important roles in CNS development (MacDonald and Johnston, 1990; Lauder, 1993). In vitro, glutamate has neurotrophic activity (Brewer and Cotman, 1989), influences neuronal survival (Balazs et al., 1988; Mount et al., 1993), and inhibits DNA synthesis in embryonic cortex (LoTurco et al., 1995). Extracellular levels of glutamate are regulated by nonvesicular transporting proteins that reduce the concentration of glutamate at the synaptic cleft (Attwell et al., 1993), thereby preventing excessive stimulation of glutamate receptors that is neurotoxic (Choi et al., 1987; Rosenberg et al., 1992). To date, four distinct high-affinity, sodium-dependent glutamate transporters have been cloned from animal and human tissue [GLAST (EAAT1), GLT-1 (EAAT2), EAAC1 (EAAT3), and EAAT4], and these proteins differ in structure, pharmacological properties, and tissue distribution (Kanai and Hediger, 1992; Pines et al., 1992; Storck et al., 1992; Kanai et al., 1993, 1995; Arriza et al., 1994). Immunohistochemical studies have revealed that GLAST and GLT-1 are localized primarily in astrocytes (Rothstein et al., 1994; Chaudhry et al., 1995; Lehre et al., 1995), whereas EAAC1 is widely distributed in neurons

Received May 27, 1997; revised Aug. 15, 1997; accepted Aug. 20, 1997.

This work was funded by National Institutes of Health National Institute of Neurological Diseases and Stroke Grants NS33958, NS36465, AG12992, and NS34100, the Muscular Dystrophy Association, The Amyotrophic Lateral Sclerosis Association, and the Cal Ripken/Lou Gehrig Fund for Neuromuscular Research.

Correspondence should be addressed to Dr. Jeffrey D. Rothstein, Department of Neurology, Johns Hopkins University School of Medicine, Meyer 5-119, 600 North Wolfe Street, Baltimore, MD 21287-7519.

Copyright (C) 1997 Society for Neuroscience $\quad 0270-6474 / 97 / 178363-13 \$ 05.00 / 0$
(Rothstein et al., 1994). EAAT4, which also has properties of a ligand-gated chloride channel (Fairman et al., 1995), is localized mainly in cerebellar Purkinje cells in rat and human CNS (Furuta et al., 1997) and in mouse brain (Yamada et al., 1996).

Alterations in glutamate transporters occur in neurodegenerative conditions that effect the adult and immature CNS. Specific glutamate transporter proteins have been found to be downregulated in amyotrophic lateral sclerosis (Rothstein et al., 1992, 1995). In perinatal models of hypoxia-ischemia, extracellular glutamate levels are increased transiently (Hagberg et al., 1987; Gordon et al., 1991), possibly by reversed glutamate transporter function (Szatkowski and Attwell, 1994) or defective uptake of glutamate (Silverstein et al., 1986). The evolution of striatal neurodegeneration in hypoxic-ischemic newborns is paralleled by abnormalities in glutamate transporters (Martin et al., 1997a). Other perinatal brain damage, such as periventricular leukomalacia, may also be related to abnormalities in the metabolism or regulation of glutamate, because oligodendrocytes from developing rat brain in culture are highly vulnerable to glutamate toxicity (Oka et al., 1993). However, the functions of the individual subtypes of glutamate transporters and their cell type expression patterns during normal CNS development remain to be clarified; furthermore, their possible roles in perinatal brain damage are not fully understood.

In situ hybridization studies indicate that mRNA transcripts for GLAST, GLT-1, and EAAC1 are expressed in subtype-specific patterns during development of mouse brain (Shibata et al., 1996; Sutherland et al., 1996). However, the relative abundance of these proteins and the precise localizations of each glutamate trans- 
porter protein have not been studied in developing rat brain. Therefore, we have used immunoblotting and immunohistochemistry with subtype-specific antibodies to study the expression and distribution of GLAST, GLT-1, EAAC1, and EAAT4 during rat CNS development.

\section{MATERIALS AND METHODS}

Antibodies. Four different subtype-specific antipeptide antibodies to glutamate transporters were used in this study. These rabbit polyclonal antibodies recognize distinct proteins at $\sim 65 \mathrm{kDa}$ (GLAST; N-terminal), $\sim 66 \mathrm{kDa}$ (GLT-1; C-terminal), $\sim 73 \mathrm{kDa}$ (EAAC1; C-terminal), and $\sim 66 \mathrm{kDa}$ (EAAT4; C-terminal). The generation and characterization of these antibodies have been described previously (Rothstein et al., 1994, 1995; Furuta et al., 1997). Antibodies to synaptophysin (mouse, monoclonal; Boehringer Mannheim, Indianapolis, IN) and GFAP (rabbit, polyclonal; Dakopatts, Copenhagen, Denmark) were used as markers for synaptic maturation and astrocytes, respectively.

Rat CNS tissue. All animal protocols were approved by the Johns Hopkins University School of Medicine Animal Care and Use Committee. Rat embryos and postnatal pups were obtained from timed pregnant Sprague Dawley rats (Charles River Laboratories, Wilmington, MA). The day of birth was designated as postnatal day 0 (P0). Embryos [embryonic day 15 (E15) and E18] were removed from anesthetized (4\% chloral hydrate) gravid rats by cesarean section. For postnatal studies, brain and spinal cord were obtained from rat pups anesthetized using hypothermia or $4 \%$ chloral hydrate.

Immunoblotting. Fresh frozen samples from rat cortex, striatum, cerebellum, and spinal cord at P1, P5, P10, P16, P26, and adult were homogenized with a Brinkmann Polytron in $20 \mathrm{~mm}$ Tris-HCl, $\mathrm{pH}$ 7.4, containing $10 \%$ sucrose, $50 \mathrm{U} / \mathrm{ml}$ Trasylol, $2 \mu \mathrm{g} / \mathrm{ml}$ leupeptin, $5 \mu / \mathrm{ml}$ antipain, 1 $\mu \mathrm{g} / \mathrm{ml}$ pepstatin A, $2.5 \mu \mathrm{g} / \mathrm{ml}$ chymostatin, and (in mM): 0.1 phenylmethylsulfonyl fluoride, 10 benzamidine, 1 EDTA, and 1 EGTA. These homogenates were first centrifuged at $1000 \times g_{\text {av }}$ for $10 \mathrm{~min}$. Then the supernatant was centrifuged at $114,000 \times g_{\text {av }}$ for $20 \mathrm{~min}$. The resulting pellet was washed in the same buffer three times by resuspension, followed by centrifugation at $114,000 \times g_{\text {av }}$ for $20 \mathrm{~min}$. The pellet was fully resuspended in this buffer supplemented with $20 \%$ glycerol. Protein concentrations were measured by a Coomassie blue-based protein assay (Bio-Rad, Hercules, CA) with bovine serum albumin as standard. Brain extracts were subjected to $10 \%$ SDS-PAGE and transferred to nitrocellulose membrane by electroblotting. Blots were blocked with $2.5 \%$ nonfat dry milk in PBS $(0.1 \mathrm{M}, \mathrm{pH} 7.2)$ and then incubated with primary antibody $(0.2 \mu \mathrm{g} / \mathrm{ml}$ GLAST, $0.017 \mu \mathrm{g} / \mathrm{ml}$ GLT-1, $0.06 \mu \mathrm{g} / \mathrm{ml}$ EAAC1, $0.135 \mu \mathrm{g} / \mathrm{ml}$ EAAT4, and $2 \mathrm{ng} / \mathrm{ml}$ synaptophysin) overnight at $4^{\circ} \mathrm{C}$. After the primary antibody incubation, membranes were washed and incubated with peroxidase-conjugated secondary antibody (1:5000) and developed with ECL (Amersham, Arlington Heights, IL). For deglycosylation experiments, protein homogenates of adult and P10 striatum were digested with $N$-glycosidase F (PNGase F) $\left(0.6 \mathrm{U} / \mathrm{ml}\right.$; Bio-Rad) for $16 \mathrm{hr}$ at $37^{\circ} \mathrm{C}$, and then the samples were subjected to SDS-PAGE and immunoblotting. Immunoreactive proteins were semiquantitatively evaluated by laser densitometry (Molecular Devices, Menlo Park, CA).

Immunohistochemistry. For light microscopy, embryonic rat tissue at E15 and E18 was immersed in 4\% paraformaldehyde in PBS. P1, P5, P10, $\mathrm{P} 16$, and P24 rat pups and adults were perfused intra-aortically with cold $0.1 \mathrm{M}$ PBS followed by $4 \%$ paraformaldehyde in PBS. Brain tissue was cryoprotected in $20 \%$ glycerol and PBS and frozen in isopentane chilled by dry ice and cut $(40 \mu \mathrm{m})$ on a sliding microtome. After pretreating with $0.1 \mathrm{M}$ periodate in Tris-buffered saline (TBS, $\mathrm{pH}$ 7.6) for $10 \mathrm{~min}$ and $1 \%$ borohydride in TBS for $10 \mathrm{~min}$, sections were incubated sequentially in $4 \%$ normal goat serum with $0.1 \%$ Triton X-100 in $0.05 \mathrm{M}$ TBS for blocking, primary antibody $(0.2 \mu \mathrm{g} / \mathrm{ml}$ GLAST, $0.17 \mu \mathrm{g} / \mathrm{ml} \mathrm{GLT}-1,0.06$ $\mu \mathrm{g} / \mathrm{ml}$ EAAC1, $0.135 \mu \mathrm{g} / \mathrm{ml}$ EAAT4, and GFAP 1:2000) with $2 \%$ normal goat serum in TBS for $48 \mathrm{hr}$ at $4^{\circ} \mathrm{C}$, secondary antibody (biotinylated goat anti-rabbit IgG) diluted at 1:400 with $2 \%$ normal goat serum in TBS, and then avidin-biotin complex diluted at 1:200 (Vector Laboratories, Burlingame, CA). Diaminobenzidine tetrahydrochloride with $\mathrm{H}_{2} \mathrm{O}_{2}$ was used as the peroxidase substrate to visualize sites of antibody binding. For immunohistochemical controls, sections of developing rat brain were incubated with transporter antibodies preabsorbed overnight with an excess $(50 \mu \mathrm{M})$ of homologous synthetic peptide corresponding to the antigen used to generate the antipeptide antibodies to the transporters, with normal rabbit IgG instead of transporter antibodies, or with the primary or secondary antibody omitted.

For electron microscopy, rats were perfused with $2 \%$ paraformaldehyde, $2 \%$ acrolein, and $0.1 \%$ glutaraldehyde in $0.1 \mathrm{M}$ phosphate buffer. Brains were removed, rinsed in cold PBS, and cut $(40 \mu \mathrm{m})$ on a vibratome. After pretreatment with $1 \%$ sodium borohydride for $10 \mathrm{~min}$, vibratome sections were prepared for immunohistochemistry using the same method for light microscopy, except that Triton X-100 was omitted. Samples from these sections were osmicated, dehydrated by graded concentrations of ethanol, and embedded to resin as described (Rothstein et al., 1994). Ultrathin sections, stained with lead citrate for $15 \mathrm{~min}$, were viewed and photographed with a Hitachi H-600 electron microscope.

\section{RESULTS}

\section{Immunoblot analysis}

Glutamate transporter antibodies detected distinct proteins with molecular weights of $65-73 \mathrm{kDa}$ in developing and adult rat CNS regions (Fig. 1A). Apparent homomultimers of GLAST, GLT-1, and EAAT4 were also observed. Aggregates of GLAST and GLT-1 were found in neocortex, striatum (Fig. $1 A$ ), cerebellum, and spinal cord, whereas aggregates of EAAT4 were found in cerebellum (Fig. 1 $A$ ) but not in neocortex, striatum, and spinal cord. These results are consistent with cross-linking studies demonstrating that glutamate transporters can form homomultimers (Haugeto et al., 1996). However, aggregates of EAAC1 were not observed in neocortex, striatum (Fig. $1 A$ ), cerebellum, or spinal cord, thereby reflecting differences among transporter subtype aggregation properties.

During postnatal development, the regional expression of glutamate transporter protein was different for each subtype (Fig. $1 A, B)$. Early postnatally and in adulthood, GLAST was most abundant in cerebellum and neocortex. GLAST expression increased with age to reach adult levels near P26 in cerebellum, neocortex, and striatum. An immunoreactive band at $\sim 90 \mathrm{kDa}$ was detected in striatum (Fig. 1A), neocortex, cerebellum, and spinal cord with GLAST antibodies. With postnatal maturation, the intensity of this $\sim 90 \mathrm{kDa}$ band decreased. Immunoreactive proteins with a comparable $M_{\mathrm{r}}$ were detected in adult striatum protein homogenates after PNGase $\mathrm{F}$ treatment (Fig. $1 A^{\prime}$ ). A nonglycosylated band at $\sim 45 \mathrm{kDa}$ was also detected after PNGase $\mathrm{F}$ treatment in striatal homogenates from P10 (data not shown) and adult rat (Fig. $1 A^{\prime}$ ) but was not detected in developing striatum under normal, undigested conditions (Fig. 1 $A$ ). The cross-reactivities of all of theses bands were completely abolished when GLAST antibodies were preabsorbed with $50 \mu \mathrm{M}$ synthetic GLAST peptide before immunoblotting of P10 striatum (data not shown).

Near birth GLT-1 protein levels were highest in spinal cord and were relatively low in cerebellum, striatum, and cortex (Fig. 1B). GLT-1 levels increased dramatically with brain maturation, notably in striatum (Fig. 1 $A$ ). EAAC1 expression was greater in immature brain than in mature brain (Fig. 1). EAAC1 expression increased with maturation, reaching maximum levels around P5$\mathrm{P} 16$, and then decreased thereafter. EAAT4 had a highly regionspecific expression pattern. EAAT4 was abundant in cerebellum (Fig. 1B). EAAT4 increased with maturation and reached a maximum level at P26 in cerebellum. In contrast, only small amounts of EAAT4 protein were detected in neocortex, striatum, and spinal cord, reaching maximum levels around P10-P16 and then decreasing with age (Fig. 1B).

During the same time course for glutamate transporter expression, synaptophysin expression increased progressively with age 

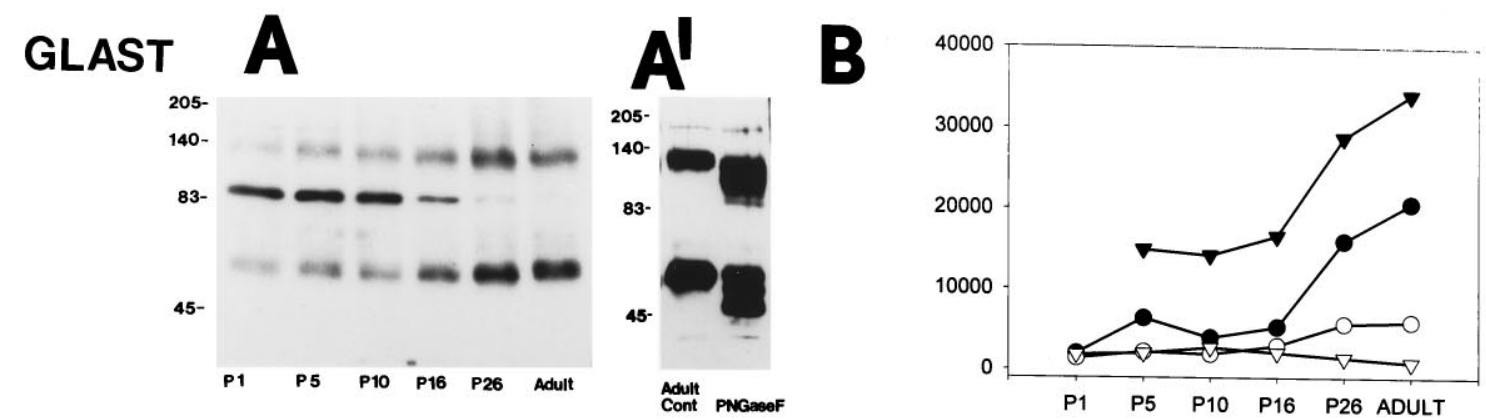

\section{GLT-1}
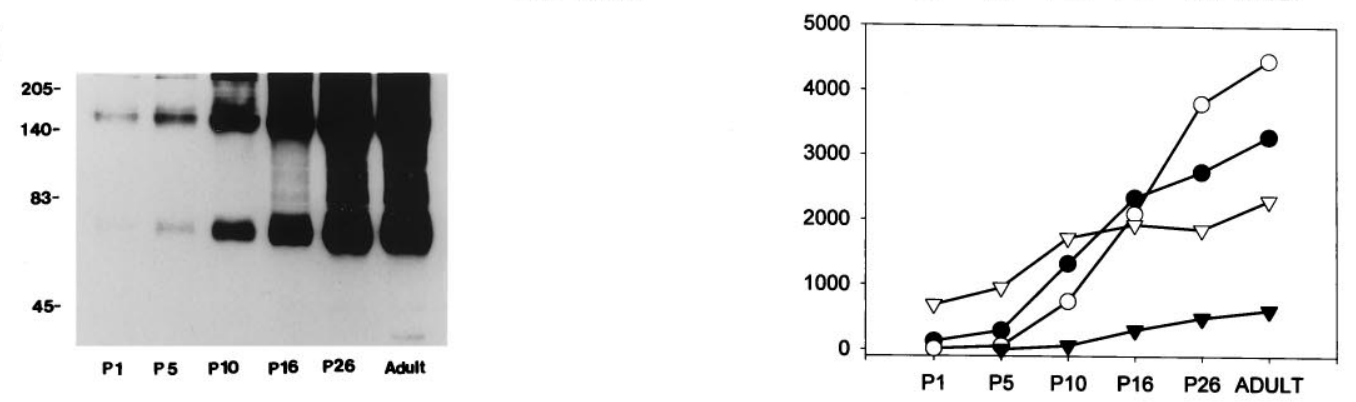

\section{EAAC 1}
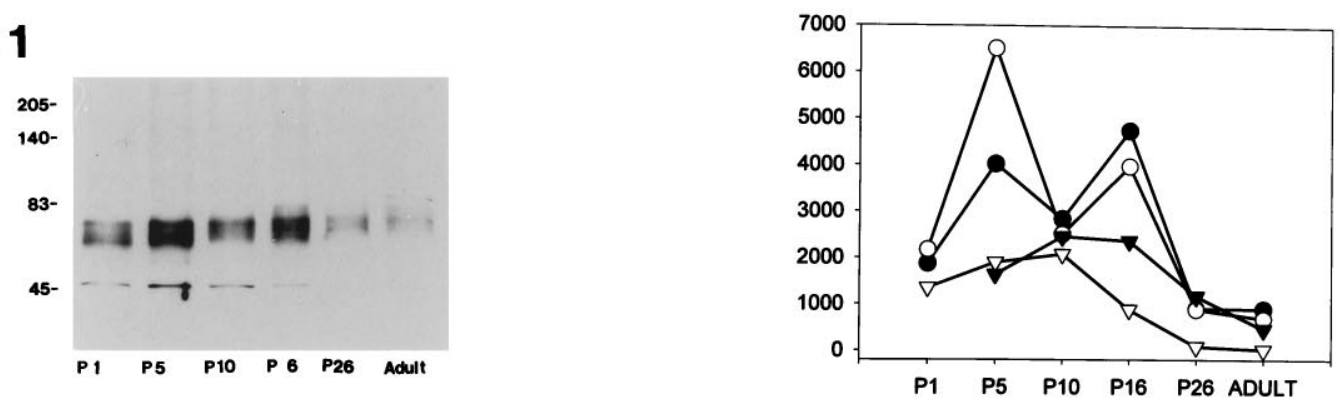

\section{EAAT 4}
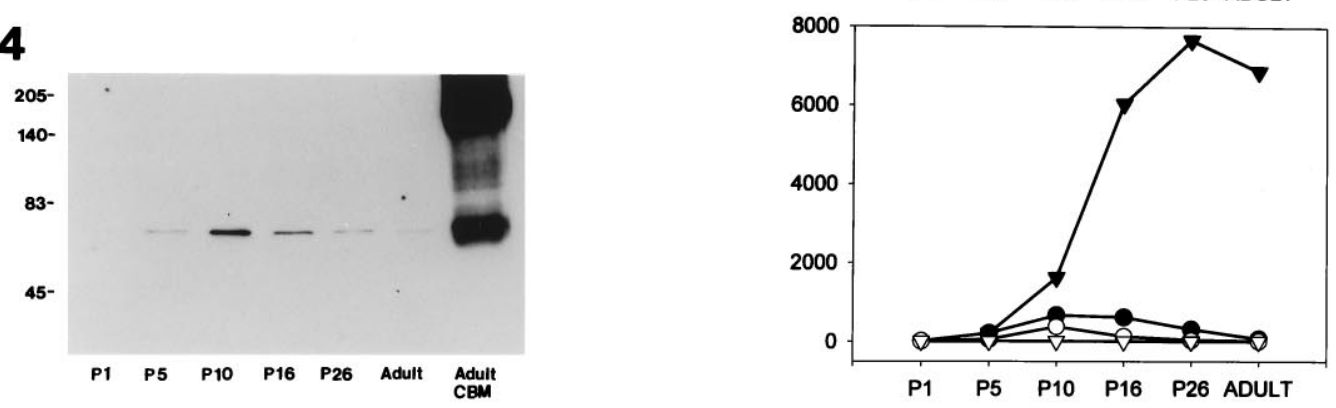

\section{Synaptophysin}
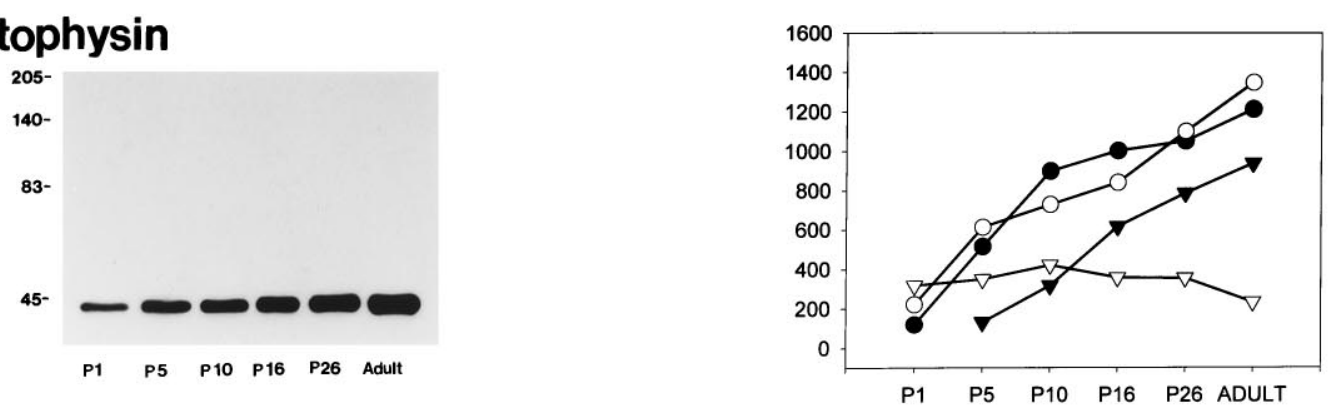

Figure 1. A, Immunoblots for glutamate transporter subtypes and synaptophysin in developing rat striatum. Adult cerebellar homogenate was loaded to the last lane of the EAAT4 blot. GLAST, GLT-1, and EAAT4 (lane with cerebellum) show dimerized bands. Immunoblots for GLAST show a band at $\sim 90 \mathrm{kDa}$ that decreases postnatally. $A^{\prime}$, This $\sim 90 \mathrm{kDa}$ band was not seen in adult striatum under normal control conditions (left lane) but appeared after deglycosylation with PNGase F treatment (right lane). $B$, Immunoblot density ( $y$-axis; arbitrary units) for each glutamate transporter subtype and synaptophysin in different CNS regions during postnatal maturation. Each lane was loaded with $10 \mu \mathrm{g}$ of protein. B, Solid circle, cortex; open circle, striatum; solid triangle, cerebellum; open triangle, spinal cord. P1, P5, P10, P16, and P26, Postnatal days; CBM, cerebellum; Adult Cont, adult control. 
Table 1. Immunoreactivities of glutamate transporter subtypes in fetal and postnatal rat CNS

\begin{tabular}{|c|c|c|c|c|c|c|c|c|c|c|c|c|c|c|c|c|c|c|c|c|c|c|c|c|}
\hline & \multicolumn{6}{|c|}{ GLAST } & \multicolumn{6}{|c|}{ GLT-1 } & \multicolumn{6}{|c|}{ EAAC1 } & \multicolumn{6}{|c|}{ EAAT4 } \\
\hline & E15 & E18 & $\mathrm{P} 1$ & $\mathrm{P} 10$ & $\mathrm{P} 24$ & Ad & E15 & E18 & $\mathrm{P} 1$ & $\mathrm{P} 10$ & $\mathrm{P} 24$ & Ad & E15 & E18 & $\mathrm{P} 1$ & $\mathrm{P} 10$ & $\mathrm{P} 24$ & Ad & E15 & E18 & $\mathrm{P} 1$ & $\mathrm{P} 10$ & $\mathrm{P} 24$ & Ad \\
\hline \multicolumn{25}{|l|}{ Neocortex } \\
\hline Marginal zone & \pm & \pm & & & & & \pm & \pm & & & & ++ & ++ & & & & & - & - & & & & & \\
\hline Layer 1 & & & \pm & \pm & + & + & & & \pm & ++ & ++ & ++ & & & ++ & ++ & + & + & & & \pm & \pm & + & \pm \\
\hline Cortical plate & & \pm & & & & & & - & & & & & & ++ & & & & & & - & & & & \\
\hline Layer II & & & \pm & \pm & + & + & & & - & + & ++ & ++ & & & + & + & + & + & & & \pm & \pm & \pm & \pm \\
\hline Layer III & & & \pm & \pm & + & + & & & - & + & ++ & ++ & & & ++ & + & + & + & & & \pm & \pm & + & \pm \\
\hline Layer IV & & & \pm & \pm & + & + & & & - & + & ++ & ++ & & & + & + & + & + & & & \pm & \pm & \pm & \pm \\
\hline Layer V & & & \pm & \pm & + & + & & & - & + & ++ & ++ & & & ++ & + & + & + & & & \pm & \pm & + & \pm \\
\hline Layer V I & & & \pm & \pm & + & + & & & - & + & ++ & ++ & & & ++ & ++ & + & + & & & \pm & \pm & \pm & \pm \\
\hline Intermediate zone & & \pm & & & & & & \pm & & & & & & \pm & & & & & & - & & & & \\
\hline Cerebral white matter & & & \pm & \pm & \pm & + & & & \pm & \pm & + & + & & & \pm & + & \pm & \pm & & & - & - & - & - \\
\hline $\begin{array}{l}\text { Ventricular and subventricular } \\
\text { zones }\end{array}$ & \pm & \pm & + & \pm & & & - & - & \pm & - & & & \pm & \pm & \pm & - & & & - & - & - & - & & \\
\hline Hippocampus & \pm & \pm & & & & & - & + & & & & & \pm & ++ & & & & & - & - & & & & \\
\hline Stratum moleculare-lacunosum & & & \pm & \pm & + & + & & & + & + & ++ & ++ & & & ++ & + & + & + & & & - & \pm & + & \pm \\
\hline Stratum radiatum & & & \pm & \pm & + & + & & & + & + & ++ & ++ & & & + & + & + & + & & & - & \pm & + & \pm \\
\hline Stratum pyramidale & & & \pm & \pm & \pm & \pm & & & - & - & + & + & & & + & ++ & + & + & & & \pm & \pm & \pm & \pm \\
\hline Stratum oriens & & & \pm & \pm & + & + & & & + & + & ++ & ++ & & & ++ & + & + & + & & & - & \pm & + & \pm \\
\hline Granular layer & & & \pm & \pm & \pm & \pm & & & - & - & + & + & & & + & ++ & + & + & & & - & \pm & \pm & \pm \\
\hline Olfactory bulb & \pm & \pm & \pm & \pm & + & + & \pm & \pm & + & + & ++ & ++ & / & \pm & + & + & + & + & - & - & - & \pm & \pm & \pm \\
\hline Ganglionic eminence & \pm & \pm & + & & & & - & - & \pm & & & & \pm & \pm & \pm & & & & - & - & - & & & \\
\hline Striatum & \pm & \pm & \pm & \pm & + & + & - & - & \pm & + & ++ & ++ & \pm & ++ & ++ & ++ & + & + & - & - & - & \pm & + & \pm \\
\hline Globus pallidus & \pm & \pm & \pm & \pm & + & + & - & + & \pm & + & ++ & ++ & \pm & ++ & + & + & + & + & - & - & - & - & \pm & \pm \\
\hline Septum & \pm & \pm & \pm & \pm & + & + & \pm & \pm & \pm & + & ++ & ++ & \pm & + & + & + & + & + & - & - & - & - & + & \pm \\
\hline Amygdala & \pm & \pm & \pm & \pm & + & + & - & + & \pm & + & ++ & ++ & \pm & ++ & + & + & + & + & - & - & - & - & \pm & \pm \\
\hline Thalamus & \pm & \pm & \pm & \pm & \pm & + & - & - & - & + & ++ & ++ & \pm & \pm & + & + & + & + & - & - & - & \pm & \pm & \pm \\
\hline Hypothalamus & \pm & \pm & \pm & \pm & + & + & \pm & + & + & + & ++ & ++ & \pm & \pm & + & + & + & + & - & - & - & - & - & - \\
\hline Tectum & \pm & \pm & \pm & \pm & \pm & + & \pm & + & \pm & + & ++ & ++ & - & + & + & ++ & + & + & - & - & - & - & - & - \\
\hline Medulla oblongata & \pm & \pm & \pm & \pm & \pm & \pm & \pm & + & + & + & + & + & + & + & + & ++ & \pm & \pm & - & - & - & - & - & - \\
\hline Cerebellar primordium & \pm & \pm & & & & & - & - & & & & & - & + & & & & & - & - & & & & \\
\hline \multicolumn{25}{|l|}{ Cerebellar cortex } \\
\hline External granular layer & & & - & - & & & & & - & - & & & & & - & - & & & & & - & - & & \\
\hline Molecular layer & & & & + & ++ & ++ & & & & \pm & ++ & ++ & & & & + & + & + & & & & + & ++ & ++ \\
\hline Purkinje cell layer & & & + & ++ & + & + & & & - & + & + & + & & & ++ & ++ & ++ & ++ & & + & + & + & + & \\
\hline Internal granular layer & & & \pm & \pm & \pm & \pm & & & - & \pm & + & + & & & - & + & + & + & & & - & - & - & - \\
\hline Deep cerebellar nucleus & & & - & \pm & \pm & \pm & & & + & + & + & + & & & + & ++ & + & + & & & - & \pm & \pm & - \\
\hline \multicolumn{25}{|l|}{ Spinal cord } \\
\hline Posterior horn & \pm & \pm & + & + & + & + & \pm & + & + & + & ++ & ++ & + & ++ & ++ & ++ & ++ & ++ & - & - & - & - & \pm & \pm \\
\hline Ventral horn & \pm & \pm & + & + & \pm & \pm & \pm & + & + & + & + & + & + & ++ & ++ & ++ & ++ & ++ & - & - & - & - & - & \pm \\
\hline White matter & - & - & \pm & \pm & \pm & \pm & ++ & ++ & + & + & + & + & - & \pm & \pm & + & + & + & - & - & - & - & - & - \\
\hline
\end{tabular}

Ad, Adult. Symbols designate no detectable $(-)$, faint $( \pm)$, moderate $(+)$, and high $(++)$ levels of immunoreactivity and not examined $(/)$.

in striatum, neocortex, and cerebellum, although synaptophysin levels were relatively constant in spinal cord with postnatal maturation (Fig. 1).

\section{Distribution of glutamate transporter subtypes in fetal and postnatal CNS}

The localizations of each glutamate transporter subtype were regionally differential during CNS development (Table 1, Figs. 2, 3 ). Brain sections used for immunohistochemical controls, including anti-GLAST, anti-GLT-1, anti-EAAC1, and anti-EAAT4 antibodies preabsorbed against their respective synthetic peptide, normal rabbit $\mathrm{IgG}$ at comparable dilutions, and omission of primary and secondary antibodies, were devoid of specific immunolabeling (data not shown). Prenatally, GLT-1 and EAAC1 were abundant in brain and spinal cord, whereas the levels of GLAST and EAAT4 were very low (Fig. $2 A-D$ ). EAAC1 was also present in some systemic organs (e.g., liver and intestine) in fetal rat (Fig.
2C). At E18, GLT-1 immunoreactivity was highly enriched in globus pallidus, amygdala, perirhinal cortex, and lateral hypothalamus but was moderately enriched in hippocampus and relatively low in the lateral ganglionic eminence, striatum, thalamus, and neocortex (Fig. 3A). GLT-1 immunoreactivity was also found in white matter in fetal brain, notably in the optic tract, fimbria, and stria terminalis, as well as in axonal pathways interconnecting neocortex, basal ganglia, and thalamus (Fig. $3 A$ ). In contrast, EAAC1 in E18 rat brain was highly enriched throughout forebrain (including neocortex, perirhinal cortex, hippocampus, amygdala, and striatum) and in the thalamic reticular nucleus (Fig. 3B).

Prominent changes in glutamate transporter localization occurred postnatally and are best illustrated in sagittal sections of $\mathrm{P} 1, \mathrm{P} 10$, and $\mathrm{P} 24$ rat (Fig. $2 E-P$ ). The pattern of expression during postnatal maturation for each glutamate transporter sub- 

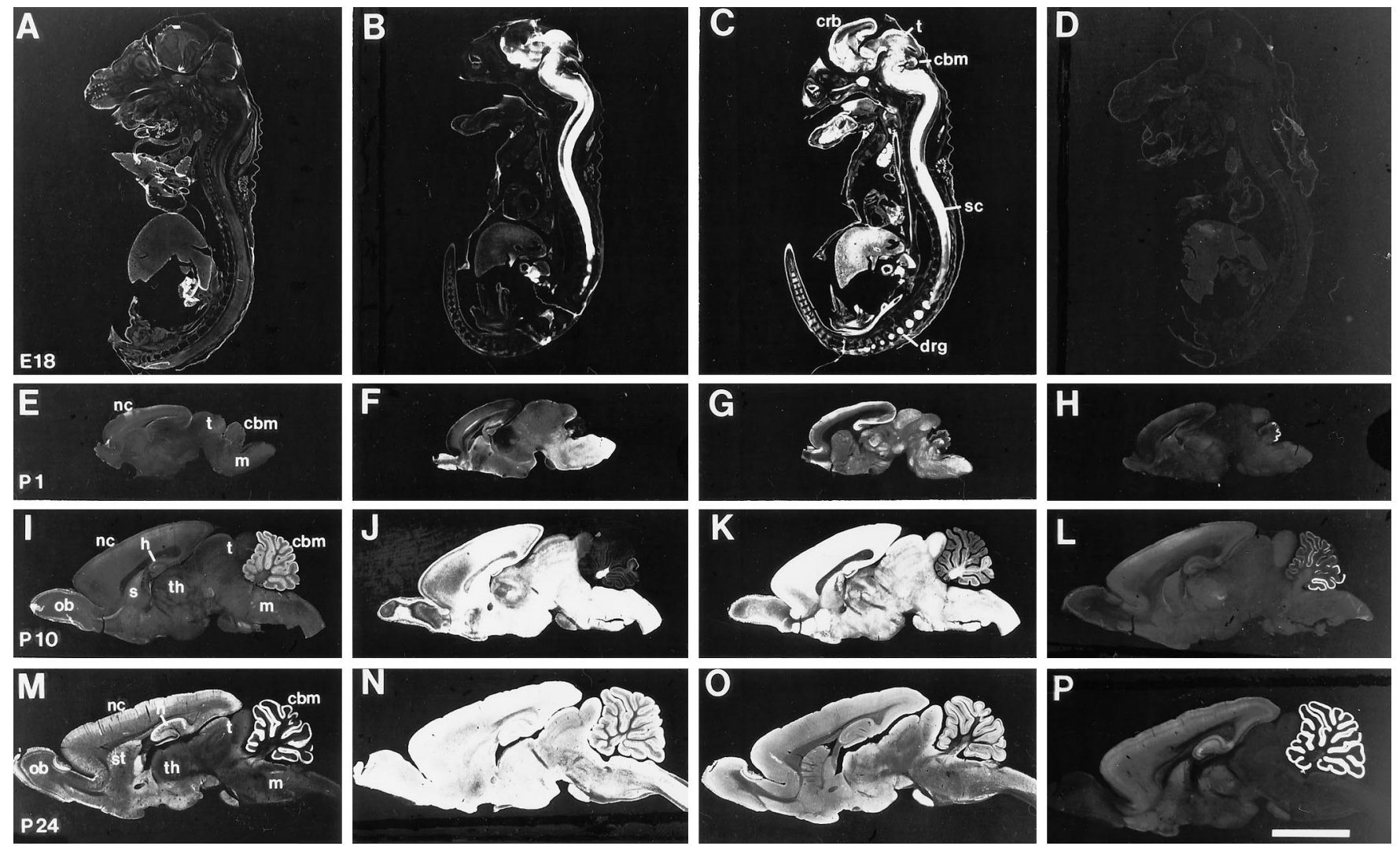

Figure 2. Dark-field photographs of immunoreactivity for GLAST $(A, E, I, M)$, GLT-1 $(B, F, J, N)$, EAAC1 $(C, G, K, O)$, and EAAT4 $(D, H, L, P)$ in rat sagittal sections at E18 $(A-D), \mathrm{P} 1(E-H), \mathrm{P} 10(I-L)$, and P24 $(M-P)$. The expression of glutamate transporter subtypes was differentially regulated during CNS development. $n c$, Neocortex; $t$, tectum; $c b m$, cerebellum; $m$, medulla oblongata; $o b$, olfactory bulb; $s$, septum; $h$, hippocampus; $t h$, thalamus; $s t$, striatum; $d r g$, dorsal root ganglion; $s c$, spinal cord. Scale bar, $5 \mathrm{~mm}$.

type was distinct. GLAST immunoreactivity was low throughout the neuraxis at P1 and then increased in cerebellum and then in forebrain with maturation (Fig. 2E,I,M). GLT-1 immunoreactivity was high in medulla and olfactory bulb at P1, increased throughout brainstem and forebrain by P10, and then became enriched in cerebellum after P10 (Fig. $2 F, J, N$ ). EAAC1 immunoreactivity was present at moderate to high levels in neocortex, hippocampus, and brainstem at P1, further increased in enrich-

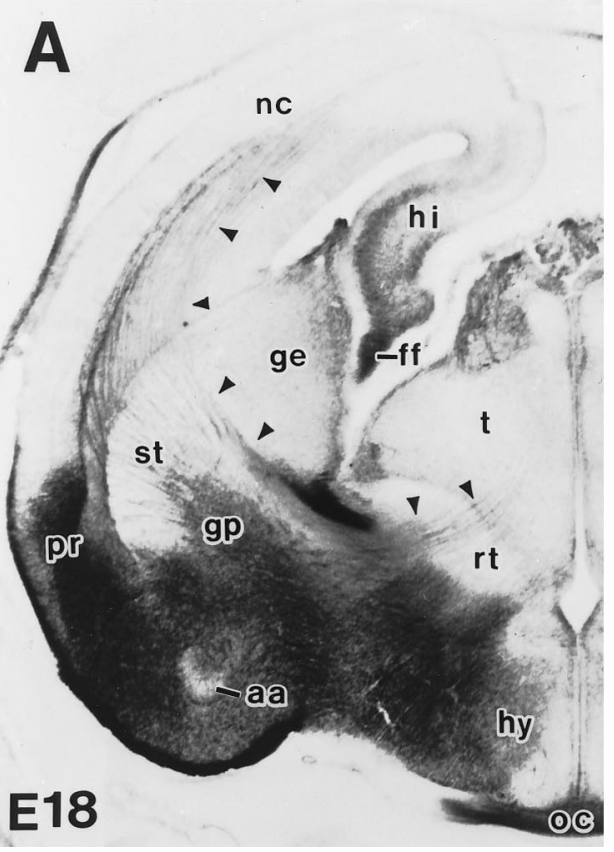

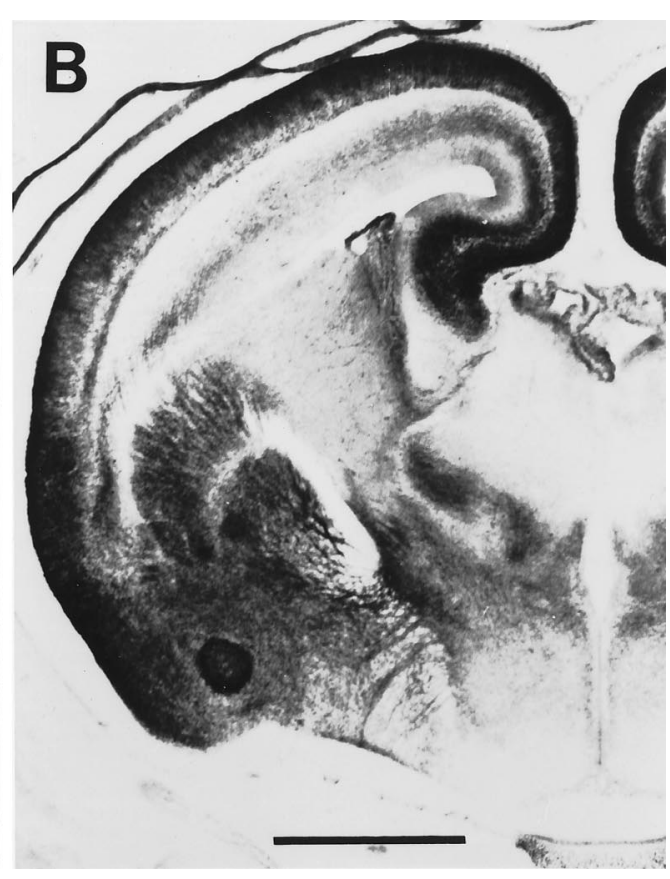

Figure 3. GLT-1 $(A)$ and EAAC1 $(B)$ immunoreactivity in rat forebrain at E18. GLT-1 was expressed in the amygdala, perirhinal cortex, hippocampus, fimbria, and optic nerve; however, sparse immunoreactivity was seen in embryonic neocortex and striatum. GLT-1 immunoreactivity was also seen along white matter pathways interconnecting neocortex, basal ganglia, and thalamus (arrowheads). In contrast, strong EAAC1 immunoreactivity was seen in neocortex, striatum, hippocampus, and reticular thalamic nucleus but not in the fimbria and optic nerve. $a a$, Anterior cortical amygdaloid nucleus; $f f$, fimbria fornix; ge, ganglionic eminence; $g p$, globus pallidus; $h i$, hippocampus; $h y$, hypothalamus; $n c$, neocortex; $o c$, optic chiasm; $p r$, perirhinal cortex; $r t$, reticular thalamic nucleus; $s t$, striatum; $t$, thalamus. Scale bar, $1 \mathrm{~mm}$. 


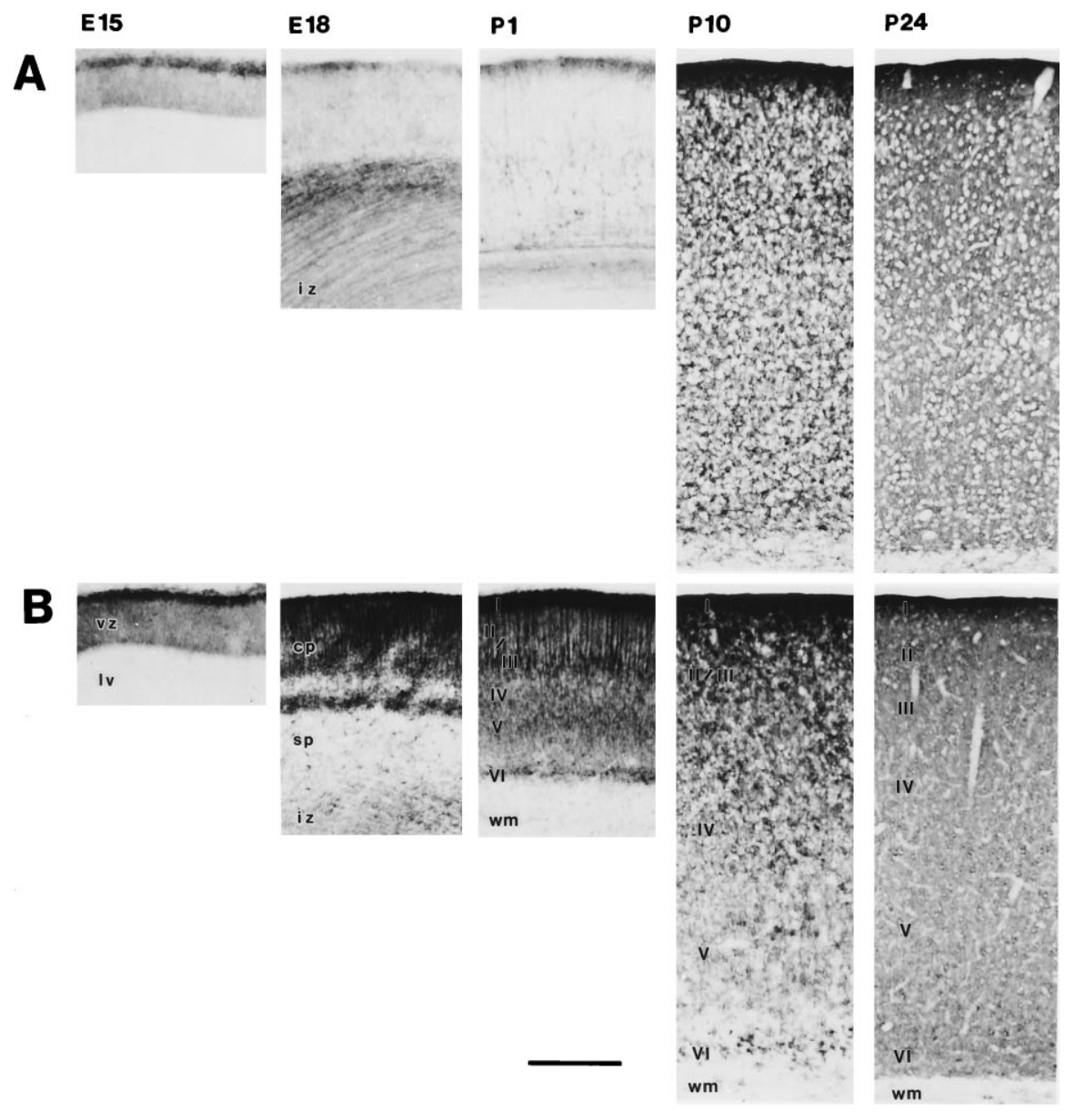

Figure 4. GLT-1 and EAAC1 immunoreactivity in the developing cerebral neocortex. $A$, GLT-1 immunoreactivity in cerebral cortex is low from E15 to P1, except in the marginal zone. GLT-1 immunoreactivity is seen transiently in the subplate and intermediate zone at P18. Postnatally, GLT-1 is expressed in astrocytic cell bodies (P10) and then throughout the neuropil (astrocytic cell processes) by P24. B, EAAC1 is enriched in marginal zone at E15. Strong EAAC1 immunoreactivity is seen throughout the cortical plate at E18 and is enriched in layer I, pyramidal cells of layer III, and layer VI at P1. Neurons in layer VI show intense immunoreactivity at P10, and then pyramidal neurons throughout layer II to layer IV and neuropil staining is seen at P24. $v z$, Ventricular zone; $l v$, lateral ventricle; $c p$, cortical plate; $s p$, subplate; $i z$, intermediate zone; $w m$, white matter; $I-V I$, cortical layers I-VI. Scale bar, $250 \mu \mathrm{m}$.

ment throughout the neuraxis by $\mathrm{P} 10$, and then decreased by $\mathrm{P} 24$ (Fig. $2 G, K, O)$. EAAT4 immunoreactivity was selectively enriched in the posterior cerebellar lobules at P1 and further increased in anterior cerebellum and also became expressed at low levels in forebrain and thalamus by P10 and then by P24 was uniformly enriched in cerebellar cortex but was expressed at low levels in neocortex, striatum, hippocampus, and thalamus (Fig. $2 H, L, P)$. Each glutamate transporter subtype showed an adult pattern of localization by P24 (Table 1, Fig. 2).

\section{Regional localization of glutamate transporters \\ Neocortex}

GLT-1 and EAAC1 were the prominent glutamate transporters in developing neocortex (Fig. 4). At E15, GLT-1 immunoreactivity was present in the marginal zone (i.e., layer I or external plexiform layer) of the telencephalic vesicle and in the subplate and intermediate zone at E18, with the latter pattern dissipating with maturation (Fig. 4A). Early postnatally and into adulthood, layer I was more enriched in GLT-1 than other layers (Fig. 4A). Astrocytic cell bodies were GLT-1 immunoreactive throughout the cortical layers at P10, and then the neuropil became intensely immunoreactive by P24 (Fig. 4A). GLAST immunoreactivity had a profile similar to that of GLT-1 in neocortex during postnatal maturation, although much less prominent than GLT-1 (Fig. 2). In contrast, in the telencephalic vesicle at E15, EAAC1 was enriched in the marginal zone and was faintly detected in the ventricular zone (Fig. 4B), and at E18, intense EAAC1 immunoreactivity was seen throughout the neuropil of the cortical plate, and scattered cell bodies were found in the subplate and inter- mediate zone (Fig. 4B). At E18, EAAC1 immunoreactivity was also present in the ganglionic eminence (Fig. $3 B$ ). At P1, EAAC1immunoreactive pyramidal cells were detected in layers III, V, and VI (Fig. 4B). Neurons in layer VI showed intense immunoreactivity at $\mathrm{P} 10$, and then by $\mathrm{P} 24$, the neuropil and neuronal perikarya in all layers were intensely immunoreactive for EAAC1 (Fig. $4 B$ ). In marked contrast to EAAC1, only faint EAAT4 immunoreactivity was observed during neocortical development (Fig. $2 H, L, P$ ) and in adult neocortex (Table 1).

\section{Striatum and globus pallidus}

In fetal rat, GLT-1 immunoreactivity was found in the medial aspect of the ganglionic eminence (Fig. $3 A$ ) but was not observed in striatum at E15 and E18 (other than in white matter bundles), whereas GLT-1 was enriched in globus pallidus (Fig. $3 A$ ). During the first postnatal week, immunoelectron microscopy showed that GLT-1 was expressed in astrocytic cell bodies and processes in the striatum (Fig. 5A), but this pattern evolved into a purely diff use localization to astrocytic processes in the neuropil by $\mathrm{P} 24$ (Fig. 5C) (Rothstein et al., 1994). As in neocortex, GLT-1 was much more abundant than GLAST in developing striatum. Faint immunoreactivity for GLAST was seen from E15 and thereafter, and astrocytes were moderately immunoreactive for GLAST at $\mathrm{P} 24$. In contrast to the astroglial glutamate transporters, EAAC1 in fetal brain was highly enriched in both striatum and globus pallidus (Fig. $3 B$ ) and was the predominant neuronal glutamate transporter in striatum compared with EAAT4 (Figs. 1, 2). Early postnatally, EAAC1 immunoreactivity was present at high levels in the striatal neuropil, corresponding to immunoreactive den- 

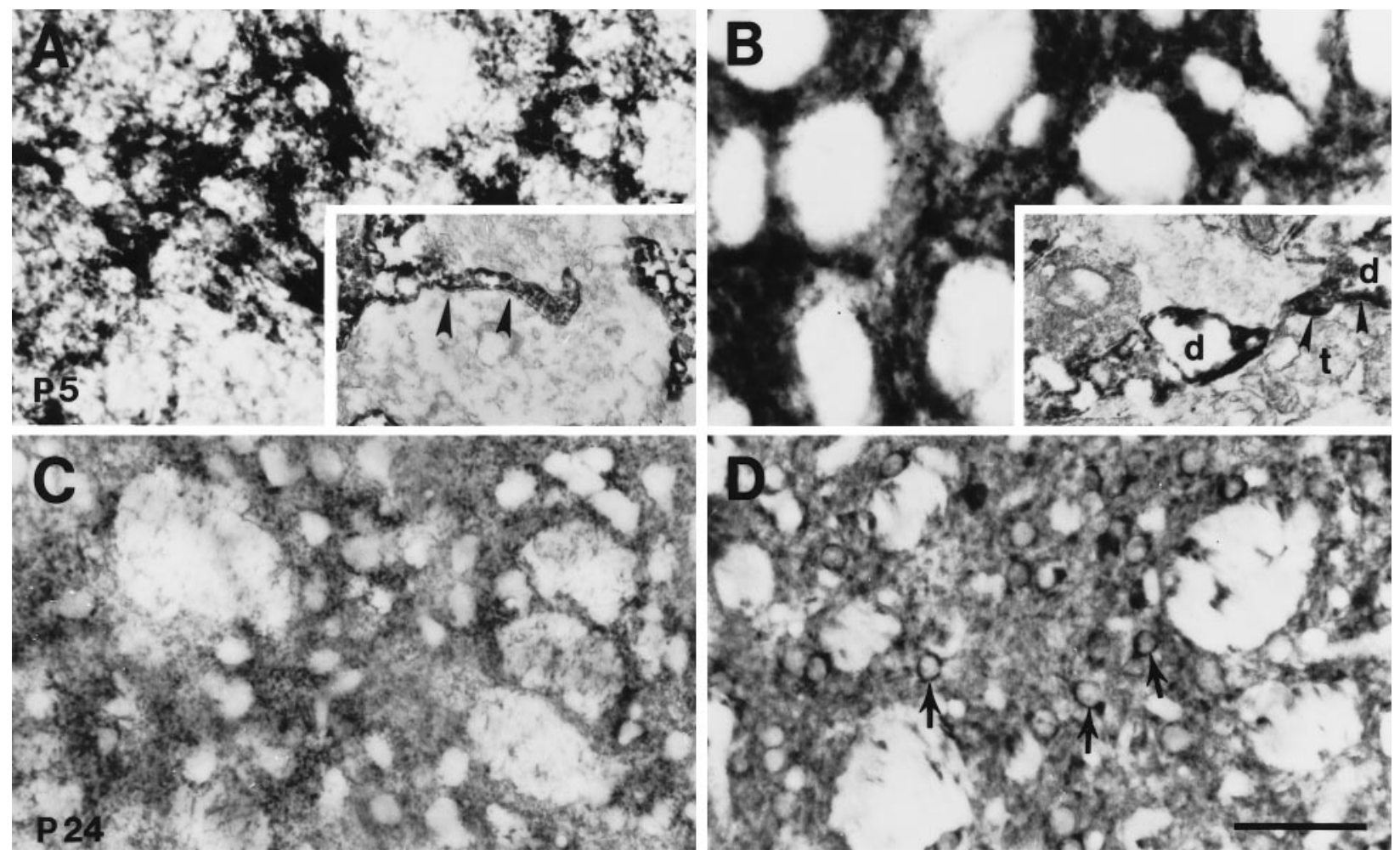

Figure 5. Patterns of GLT-1 $(A, C)$ and EAAC1 $(B, D)$ immunoreactivity within the striatum at P5 and P24 $(C, D)$ were different. GLT-1 immunoreactivity was mainly seen in astrocytic cell bodies at P5 $(A)$, and then diff use neuropil staining of astrocytic processes around neurons was seen at P24 $(C)$. In contrast, EAAC1 was diffusely expressed in striatum at P5 $(B)$ and then localized to medium-sized neurons at P24 $(D)$. Immunoelectron microscopy showed GLT-1 immunoreactivity in astrocytic process $(A$, inset, arrowheads) and EAAC1 immunoreactivity in dendrites $(B$, inset, $d)$ at P5. Arrowheads in $B$, inset, Postsynaptic density; $d$, dendrite; $t$, terminal. Scale bar: $A-D, 50 \mu \mathrm{m} ; A$, inset, $760 \mathrm{~nm} ; B$, inset, $460 \mathrm{~nm}$.

drites by immunoelectron microscopy (Fig. 5B). By P24, mediumsized principal neurons of the striatum and the neuropil were EAAC1-immunoreactive, but the intensity of immunoreactivity at P24 was lighter than during the first postnatal week (Fig. 5), consistent with the developmental down-regulation seen by immunoblotting (Fig. 1A).

\section{Hippocampus}

During embryogenesis, GLT-1 immunoreactivity was present in the gray matter of the subiculum, CA1, CA3, and dentate gyrus and was highly enriched in the fimbria (Fig. $3 A$ ). Prenatally, EAAC1 was highly enriched throughout the hippocampal formation gray matter but was not detected in the fimbria (Fig. $3 B$ ). GLAST and EAAT4 immunoreactivities were very faint to undetectable in fetal hippocampal formation. During postnatal development of hippocampus, both GLT-1 and EAAC1 immunoreactivities were more enriched than GLAST and EAAT4 immunoreactivities (see Figs. 2, 6). The localizations of GLT-1 and $\mathrm{EAAC} 1$ were in part complementary during early postnatal maturation of hippocampus. At P1 and P10, GLT-1 was enriched in the neuropil of the stratum oriens, stratum radiatum, and stratum lacuosum-moleculare of CA1 and CA 3 and in the molecular and infragranular layers of the dentate gyrus, but the pyramidal and granule cell body layers had comparatively low GLT-1 immunoreactivity (Fig. 6A,C). EAAC1 immunoreactivity, in contrast, was prominent in the pyramidal cell body layers of CA1 and CA3 and in the granule cells of dentate gyrus at P10. Although EAAC1 was also present in the neuropil of the stratum oriens, stratum radiatum, and stratum lacuosum-moleculare of CA1 and CA3 and in the molecular layer of the dentate gyrus, EAAC1 was notably low in the infragranular layer at P10 (Fig. $6 B, D)$. By P24, both GLT1 and EAAC1 were localized throughout the hippocampus, with both transporters highly enriched in the molecular layer of the infrapyramidal blade of the dentate gyrus (Fig. 6E,F).

\section{Cerebellum}

The cellular specificity in the expression of subtypes of glutamate transporters was uniquely observed in the developing rat cerebellar cortex (Fig. 7). At P1 and P5, specific immunorectivity for GLAST or GLT-1 was not observed in the external granular layer (Fig. 7). At P5, some cells in the Purkinje cell layer expressed GLT-1 immunoreactivity (Fig. $7 F$ ) and likely corresponded to maturing Bergmann glia, because Bergmann glial cell bodies and radial processes were distinctly immunoreactive for GLT-1 and GLAST by P10 (Fig. 7I,J). Subsets of cells in the internal granular layer were faintly immunoreactive for GLAST or GLT-1 at P5 and P10 (Fig. 7F,I). By P24, the neuropil of the molecular layer contained intense GLAST and GLT-1 immunoreactivity, and immunoreactive glial sheaths surrounded unlabeled Purkinje cell bodies (Fig. $7 N$ ). In contrast, throughout maturation and in adulthood, Purkinje cell bodies and their dendrites were intensely immunoreactive for EAAC1 and EAAT4 (Fig. 7C,D,G,H, $K, L, O, P)$. The internal granular layer had differential patterns of expression for EAAC1 and EAAT4 in immature and mature cerebellum. As the external granular layer dissipated and as dendritic shafts and spines of Purkinje cells matured, the neuropil 

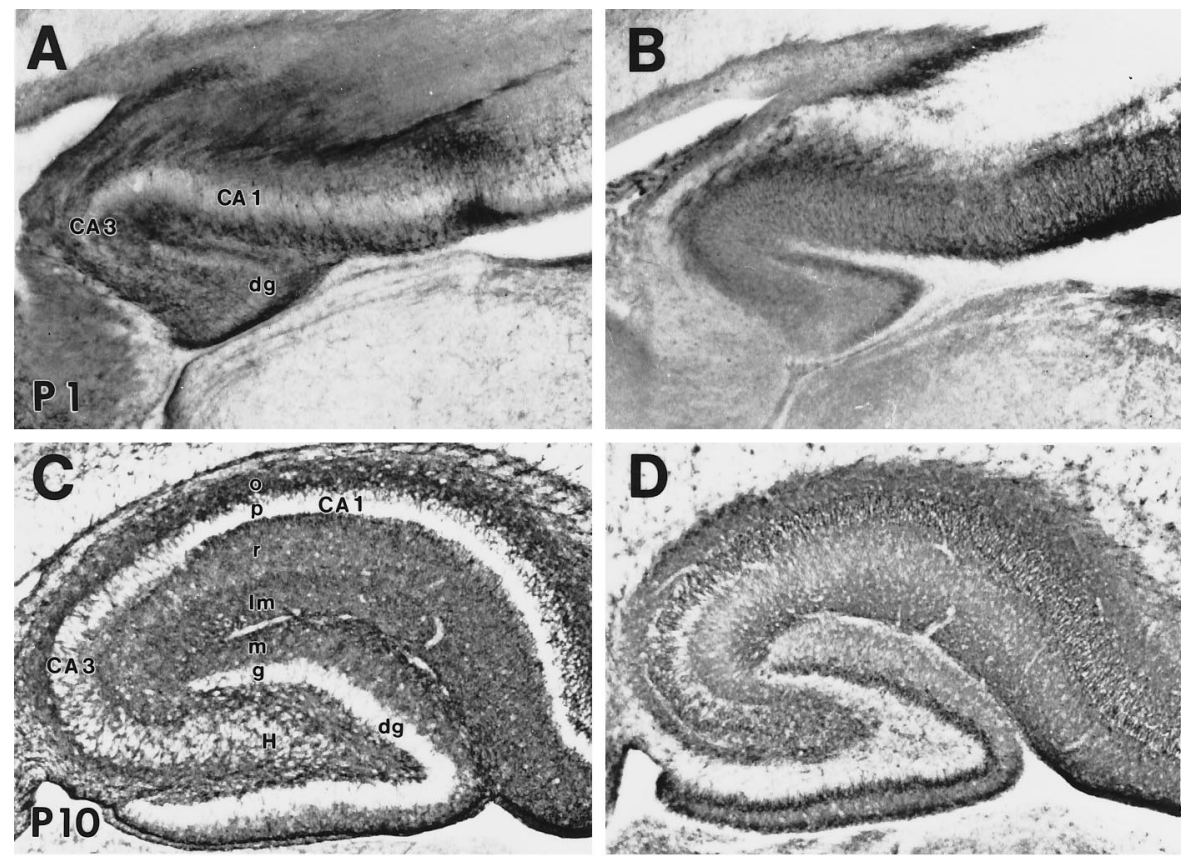

Figure 6. Immunoreactivity for GLT-1 $(A, C, E)$ and EAAC1 $(B, D, F)$ in parasagittal sections of hippocampus at $\mathrm{P} 1(A, B), \mathrm{P} 10(C, D)$, and $\mathrm{P} 24(E$, $F)$. GLT-1 and EAAC1 immunoreactivities were seen throughout development and into adulthood. Postnatally, GLT-1 was localized in astrocytes. EAAC1 was seen in neurons and was more enriched in pyramidal and granule cells at $\mathrm{P} 10(D)$. $C A 1$ and $C A 3$, Cornu Ammon's subfields 1 and 3; $d g$, dentate gyrus; $H$, hilus; $o$, stratum oriens; $p$, stratum pyramidale; $r$, stratum radiatum; $l m$, stratum lacuosum-moleculare; $m$, molecular layer; $g$, granular layer. Scale bar, $500 \mu \mathrm{m}$.
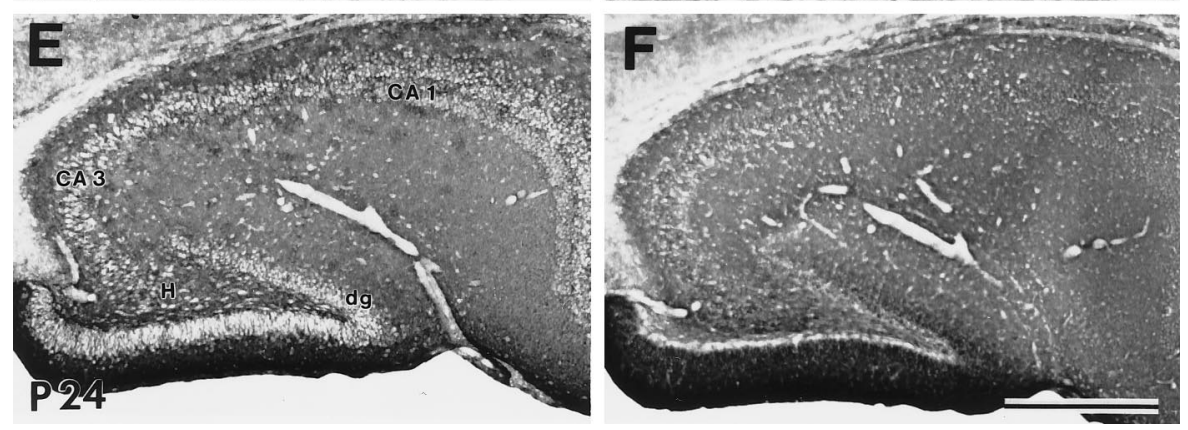

of the molecular layer became correspondingly more enriched in EAAC1 and EAAT4. EAAC1 and EAAT4 localization revealed that the posterior lobules of cerebellar cortex mature earlier than anterior lobules.

\section{Spinal cord}

In embryonic spinal cord, GLT-1 and EAAC1 were the major glutamate transporters, whereas GLAST and EAAT4 were expressed and low levels (see Figs. $1 B, 2,8$ ). The changes in the localization of GLT-1 (Fig. 8C,G,K,O,S) and EAAC1 (Fig. $8 D, H, L, P, T)$ are shown in transverse sections of spinal cord; Nissl-stained sections are shown for neuroanatomical orientation and regional compartmentation (Fig. 8A,E,I,M,Q), and GFAPstained sections are shown for an astrocyte phenotype marker (Fig. 8B,F,J,N,P). Intense GLT-1 immunoreactivity was seen in the white matter and dorsal horn at E15 and E18 (Fig. 8C,G), whereas GLT-1 was more enriched in astrocytes of gray matter by P24 (Fig. 8S). GFAP was initially expressed in the medioventral white matter of spinal cord between E15 and E18 (Fig. 8B,F); however, GLT-1 immunoreactivity was seen before GFAP expression. The localizations of GFAP and GLT-1 were similar after P10. EAAC1 immunoreactivity was present in dorsal root ganglia (Figs. $2 C, 8 D$ ) and spinal cord gray matter from E15 to adulthood (Fig. 8) and was enriched in both dorsal and ventral horns in developing and adult spinal cord. During development and in adults, motor neurons were immunoreactive for EAAC1 but not GLAST, GLT-1, or EAAT4 (Fig. 8).

\section{DISCUSSION}

The expression and localization of glutamate transporter protein subtypes during embryonic and postnatal development of the rat CNS were analyzed with subtype-specific antibodies to GLAST, GLT-1, EAAC1, and EAAT4. The transporter subtype specificities of these antibodies have been shown previously (Rothstein et al., 1994; Furuta et al., 1997). Several general findings were derived from this study. We found that the different molecular subtypes of glutamate transporters have very distinct, but coordinated, regional patterns of expression during CNS development, and that the cell type specificity in the expression of distinct glutamate transporters subtypes is, for the most part, similar in developing and adult CNS, except for a possible transient localization of GLT-1 in axons in embryonic CNS. In addition, the regulated expression of glutamate transporter subtypes appears to segregate within different CNS regions. For example, the dominant astroglial and neuronal glutamate transporters in cerebellum are GLAST and EAAT4, respectively, whereas GLT-1 and EAAC1 are the primary astroglial and neuronal glutamate transporters, respectively, in forebrain, brainstem, and spinal cord.

\section{Comparison of glutamate transporter protein and mRNA distributions in developing CNS}

Many similarities are found when comparing our data on the regional expression and localization of glutamate transporter 

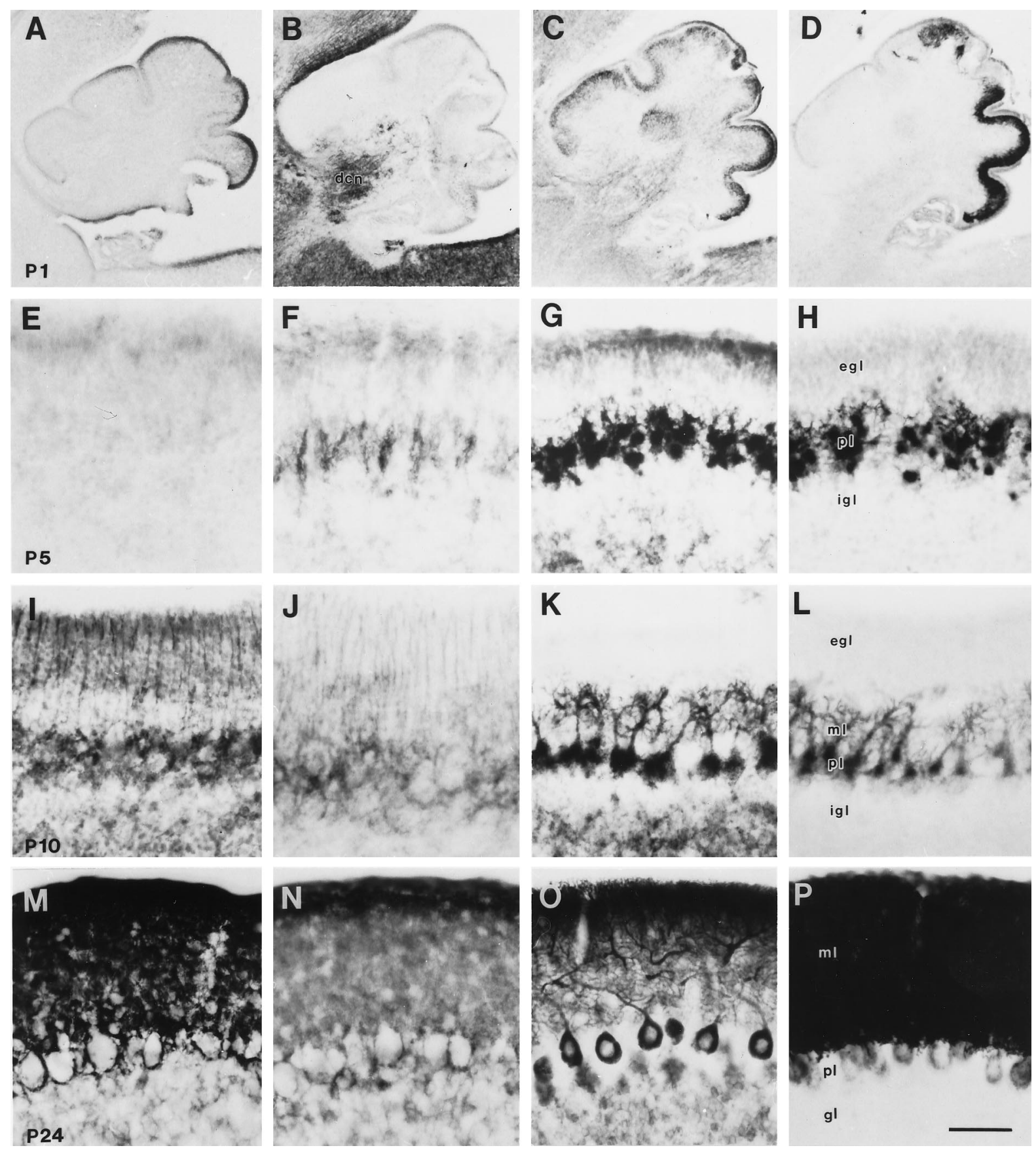

Figure 7. Immunoreactivity for GLAST $(A, E, I, M)$, GLT-1 $(B, F, J, N)$, EAAC1 $(C, G, K, O)$, and EAAT4 $(D, H, L, P)$ in cerebellar cortex at P1 $(A-D)$, P5 $(E-H)$, P10 $(I-L)$, and P24 $(M-P)$. Subsets of cells, most likely developing Bergmann glia, in the Purkinje cell layer at P5 show slight GLT-1 immunoreactivity. In P10 cerebellum, fine processes of Bergmann glia are immunoreactive for GLAST and GLT-1. EAAC1 and EAAT4 are expressed in Purkinje cells from P1. EAAT4 expression in Purkinje cells began in the caudal part of the cerebellum. At P24, all four glutamate transporter subtypes are abundant in the cerebellar cortex; GLAST and GLT-1 are enriched in Bergmann glia and molecular layer, whereas EAAC1 and EAAT4 are expressed in Purkinje cells and molecular layer. $d c n$, Deep cerebellar nucleus; $m l$, molecular layer; $g l$, granular layer; $e g l$ and $i g l$, external and internal granular layers, respectively; $p l$, Purkinje cell layer. Scale bar: $A-D(P 1), 400 \mu \mathrm{m} ; E-P(P 5, P 10, P 24), 50 \mu \mathrm{m}$.

proteins in developing rat CNS to results on glutamate transporter mRNA localization in developing mouse CNS; however, some differences are present as well (Shibata et al., 1996; Sutherland et al., 1996). GLAST (EAAT1) protein and mRNA are present predominantly in cerebellum early postnatally and are both present at high levels in adult cerebellum (Shibata et al., 1996; Sutherland et al., 1996); however, GLAST protein levels increase postnatally in forebrain as well, whereas GLAST mRNA levels are relatively constant in forebrain postnatally (Sutherland et al., 1996). In contrast, GLT-1 (EAAT2) protein and mRNA levels both increase throughout the neuraxis postnatally (Shibata et al., 1996; Sutherland et al., 1996). Both GLAST and GLT-1 mRNA have been detected in white matter in embryonic CNS (Sutherland et al., 1996). We have found that expression of 

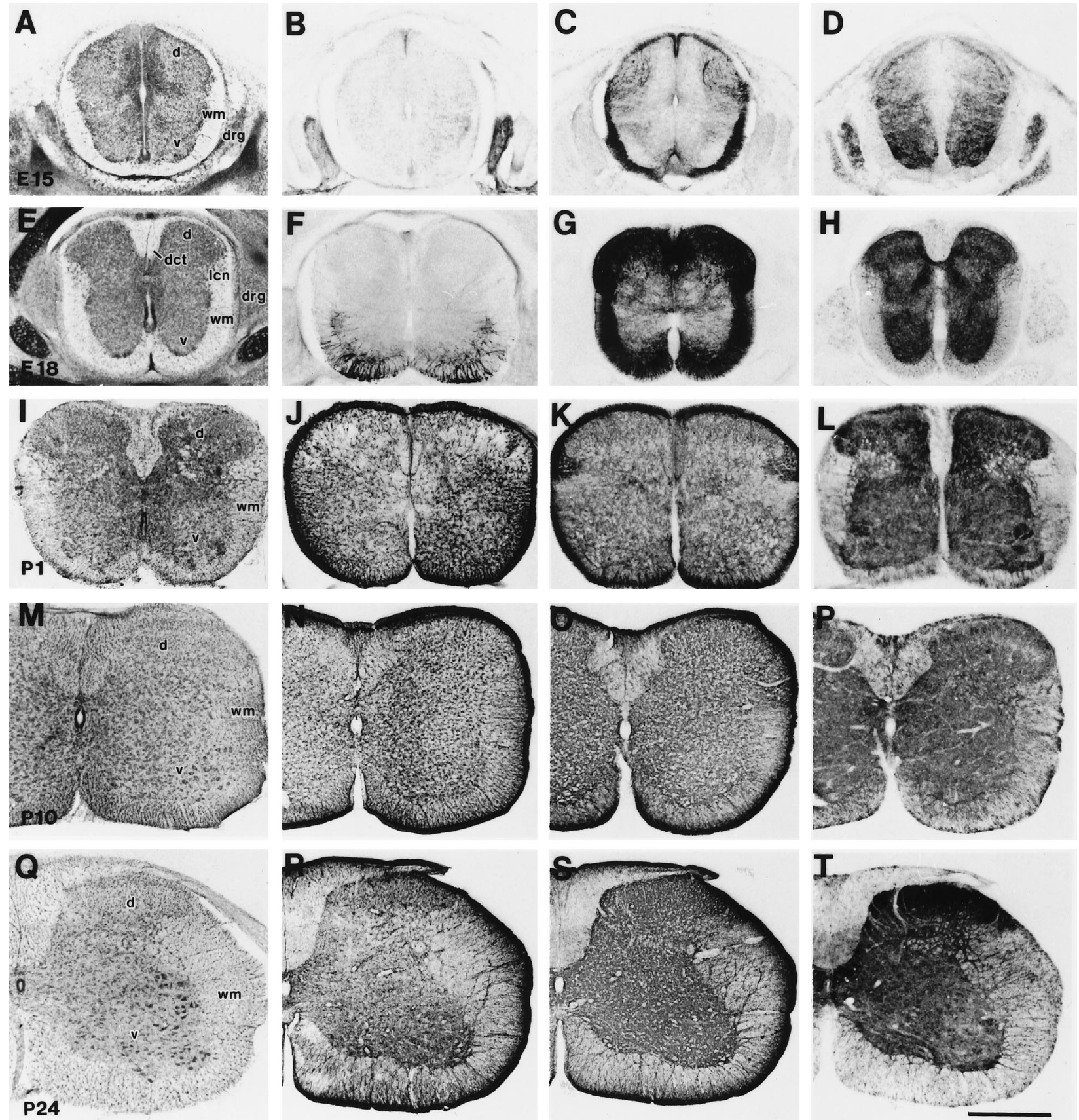

Figure 8. Cresyl violet staining $(A, E, I, M, Q)$ and immunoreactivity for GFAP $(B, F, J, N, R)$, GLT-1 $(C, G, K, O, S)$, and EAAC1 $(D, H, L, P, T)$ in cervical spinal cord at E15 $(A-D)$, E18 $(E-H), \mathrm{P} 1(I-L), \mathrm{P} 10(M-P)$, and P24 $(Q-T)$. GFAP was expressed at E18 in the medioventral white matter $(F)$. Intense GLT-1 immunoreactivity was seen in white matter and dorsal horn at E15 $(C)$ and E18 $(G)$, although GLT-1 was more expressed in astrocytes of gray matter after P10 $(O, S)$. EAAC1 was localized in gray matter throughout embryonic to postnatal periods. $d$, Dorsal horn; $v$, ventral horn; $w m$, white matter; $d r g$, dorsal root ganglion; $d c t$, dorsal corticospinal tract; lcn, lateral cervical nucleus. Scale bar, $500 \mu \mathrm{m}$.

GLT-1 protein (but not GLAST protein) is very prominent in some white matter tracts in fetal rat CNS (Figs. $3 A, 4 A, 8 C, G, K$ ) and fetal ovine brain (Northington et al., 1997). With regard to cellular localization of glutamate transporter mRNA in developing mouse, GLAST mRNA was found in cortical plate neurons; transcripts for GLAST and GLT-1 were detected in dentate gyrus granule cells early postnatally; GLT-1 mRNA was found in CA3 stratum pyramidale neurons; and GLAST mRNA was observed in some Purkinje cells (Sutherland et al., 1996). In developing rat CNS, we did not detect GLAST or GLT-1 immunoreactivity in the cell bodies of these neuronal populations. Yet, in fetal ovine brain, we have detected, with the same antibodies used here, GLT-1 immunoreactivity in neuronal subsets in the subplate, the Purkinje cell layer, and some cranial nerve motor nuclei, whereas in near-term brain, a purely astroglial localization is observed, and by immunoblotting this antibody is highly specific for GLT-1 in fetal sheep brain (Northington et al., 1997). Thus, it seems possible that species differences exist in the cellular expression of some glutamate transporters during CNS development, but the functional relevance of this possibility remains unclear. 


\section{Glutamate transporter expression during morphogenesis}

The embryonic neocortex in vertebrates consists of the ventricular, subventricular, intermediate, and marginal zones (Jacobson, 1991), with radial glia and early postmitotic pyramidal neurons anchoring to the marginal zone by their distal processes or apical dendrites (Marín-Padilla, 1992). Stratification of cerebral cortex is completed postnatally in rat (Jacobson, 1991). During corticogenesis, EAAC1 was highly enriched in the marginal zone, although GLT-1 and GLAST were only faintly to moderately detected. Furthermore, perinatally, EAAC1 was more enriched than GLAST, GLT-1, and EAAT4 in cerebral cortex. Thus, during corticogenesis at late embryonic and early postnatal periods, glutamate transport by neurons, specifically via EAAC1, may predominate over astroglial transport of glutamate. Expression of EAAC1 at high levels in the external plexiform layer appears to coincide with the maturation of the apical dendritic bouquets of pyramidal neurons (Marín-Padilla, 1992) at a time when nonNMDA glutamate receptors are also highly enriched in the marginal zone (Furuta et al., 1995; Herrmann, 1996; Martin et al., 1997b).

Glutamatergic mechanisms are operative in undifferentiated proliferative zones during embryogenesis. Glutamate activates non-NMDA glutamate receptors in the ventricular zone (LoTurco et al., 1995), and AMPA receptor protein is expressed in proliferative zones in developing ferret (Herrmann, 1996), rat (Martin et al., 1997b), and ovine brain (Furuta et al., 1995). GLAST and GLT-1 mRNAs are expressed in the ventricular zone of embryonic mouse brain (Shibata et al., 1996; Sutherland et al., 1996); although, at low levels, we found GLAST immunoreactivity in the ventricular and subventricular zones of the telencephalon and GLT-1 and EAAC1 immunoreactivities in the ganglionic eminence. Subsets of progenitor cells may therefore have an uncommitted glutamate transporter phenotype, with cell type specificity for glutamate transporter phenotype occurring with differentiation.

\section{Coordinated expression of EAAC1 and GLT-1 in neonatal brain}

We found that EAAC1 protein expression was greater in newborn brain compared with the level in adult brain. Furthermore, EAAC1 was enriched in striatum at a time when GLT-1 immunoreactivity was relatively low and when synaptic maturity (as determined by synaptophysin levels) was incomplete. This observation may reflect an initial phase of excessive outgrowth of dendritic branches followed by a pruning of redundant dendrites (Jacobson, 1991). Alternatively, these findings may signify a coordinated expression of glutamate transporter subtypes with synaptic maturation. Thus, in immature forebrain, when mature synaptic patterns have not yet been established, glutamate transport by neurons may be dominant, whereas astroglial glutamate transport may predominate in mature forebrain at a time when synaptic innervation is fully developed. This idea is consistent with the finding that GLT-1 is induced in undifferentiated astrocytes by the presence of neurons in vitro (Swanson et al., 1997). In addition, GLT-1 and GLAST, but not EAAC1, are mainly responsible for in vivo regulation of extracellular glutamate in adult brain (Rothstein et al., 1996), consistent with the finding that GLT-1 expression is transiently reduced in adult striatum after corticostriatal deafferentation (Ginsberg et al., 1995). Finally, EAAC1 may serve metabolic functions for neurons, because it is widely expressed outside the nervous system (Fig. $2 c$ ). For example, it may provide glutamate for resynthesis of GABA in GABAergic presynaptic terminals, where the protein has been localized (Rothstein et al., 1994).

\section{GLT-1 localization in white matter during late embryogenesis}

Transient expression of GLT-1 was observed in white matter tracts in fetal brain and spinal cord. Several possibilities may account for this observation. GLT-1 in embryonic white matter may be in astroglia; however, in spinal cord white matter, GLT-1 enrichment preceded the enrichment of GFAP. GLT-1 may be localized in myelin sheaths of developing oligodendroglia that closely contact growing axons; however, oligodendrocytes first appear at P0 in rat optic nerve (Miller et al., 1985), although we found the optic tract enriched in GLT-1 at E18. Alternatively, although GLT-1 is primarily astroglial in adult rat brain (Rothstein et al., 1994; Chaudhry et al., 1995; Lehre et al., 1995), in fetal rat brain, GLT-1 protein may also be expressed in neurons at levels in the cell body that are below the limits of immunological detection, but at levels sufficient for detection in growing axons. This latter possibility is supported by in situ studies showing GLT-1 mRNA in hippocampal neurons in adult (Torp et al., 1994; Lehre et al., 1996; Schmitt et al., 1996) and developing (Sutherland et al., 1996) brain and by immunocytochemical studies showing a transient expression of GLT-1 protein in neuronal cell bodies and axons in fetal ovine brain (Northington et al., 1997).

\section{Differential post-translational modification of GLAST during CNS development}

Neurotransmitter transporter proteins generally contain multiple consensus sites for N-linked glycosylation in the large extracellular loop (Patel, 1997). N-linked glycosylation of GLAST homomultimers may be developmentally regulated. We detected a prominent $\sim 90 \mathrm{kDa}$ band that may possibly correspond to a nonglycosylated dimerized species of GLAST monomers (45 $\mathrm{kDa}$ ). Alternatively, the $90 \mathrm{kDa}$ species could reflect a protein complex of a distinct developmentally regulated protein that closely interacts with GLAST and thereby cross-reacts with GLAST antibodies. Proteins that interact with glutamate transporter subtypes have been suggested (Arriza et al., 1997). By immunoblotting, the levels of this $90 \mathrm{kDa}$ species decreased postnatally, whereas glycosylated GLAST monomers and dimers increased with maturation. Splice variants or truncated forms of GLAST have not been found by Northern blot analysis using P10 striatum RNA (G. Lin, unpublished observations). Developmental-dependent changes in glycosylation have also been observed with dopamine transporters during postnatal maturation (Patel et al., 1994). The developmental regulation in glycosylation may be explained by the availability of different glycosyltransferases during ontogenesis (Biol et al., 1987); yet, the selectivity for this change in the post-translational modification of GLAST (but not other glutamate transporters) is unclear. In vitro studies have revealed that the extent of N-linked glycosylation has a negligible effect on the transport activity of GLAST expressed in Xenopus oocytes (Conradt et al., 1995). However, the time course for the evolution of the adult pattern of GLAST glycolysation appears to correspond roughly with the progressive attainment of adult synaptophysin levels in the striatum; thus, the post-translational processing of GLAST and synaptic innervation may mature in parallel. 


\section{Conclusion}

Expression of glial glutamate transporter GLAST and GLT-1 increased with brain maturation, whereas expression of neuronal glutamate transporter EAAC1 was greater in newborn compared with adult brain. Expression of another neuronal glutamate transporter, EAAT4, increased with maturation in cerebellum. Immunohistochemically, the most dynamic changes were observed in a GLT-1 expression pattern. In the embryonic stage at E18, transient expression of GLT-1 was seen in white matter. Thus, the different subtypes of glutamate transporters are expressed in regionally distinct patterns, with glial and neuronal transporter expression appearing in a coordinated manner during CNS development.

\section{REFERENCES}

Arriza JL, Fairman WA, Wadiche JI, Murdoch GH, Kavanaugh MP, Amara SG (1994) Functional comparisons of three glutamate transporter subtypes cloned from human motor cortex. J Neurosci 14:5559-5569.

Arriza JL, Eliasof S, Kavanaugh MP, Amara SG (1997) Excitatory amino acid transporter 5, a retinal glutamate transporter coupled to a chloride conductance. Proc Natl Acad Sci USA 94:4155-4160.

Attwell D, Babour B, Szatkowski M (1993) Nonvesicular release of neurotransmitter. Neuron 11:401-407.

Balazs R, Jorgensen OS, Hack N (1988) N-Methyl-D-aspartate promotes the survival of cerebellar granule cells in culture. Neuroscience 27:437-451.

Biol MC, Martin A, Richard M, Louisot P (1987) Developmental changes in intestinal glycosyl-transferase activities. Pediatr Res 22:250-256.

Brewer GL, Cotman CW (1989) NMDA receptor regulation of neuronal morphology in cultured hippocampal neurons. Neurosci Lett 99:268-273.

Chaudhry FA, Lehre KP, van Lookeren Campagne M, Ottersen OP, Danbolt NC, Storm-Mathisen J (1995) Glutamate transporters in glial plasma membranes: highly differentiated localizations revealed by quantitative ultrastructural immunocytochemistry. Neuron 15:711-720.

Choi DW, Maulucci-Gedde M, Kriegstein AR (1987) Glutamate neurotoxicity in cortical cell culture. J Neurosci 7:357-368.

Conradt M, Storck T, Stoffel W (1995) Localization of N-glycosylation sites and functional role of the carbohydrate units of GLAST-1, a cloned rat brain L-glutamate/L-aspartate transporter. Eur J Biochem 229:682-687.

Fairman WA, Vandenberg RJ, Arriza JL, Kavanaugh MP, Amara SG (1995) An excitatory amino-acid transporter with properties of a ligand-gated chloride channel. Nature 375:599-603.

Fonnum F (1984) Glutamate: a neurotransmitter in mammalian brain. J Neurochem 42:1-11.

Furuta A, Blue ME, Koehler RC, Traystman RJ, Martin LJ (1995) Expression of non-NMDA receptor subtypes is time- and laminardependent during corticogenesis. Soc Neurosci Abstr 21:840.

Furuta A, Martin LJ, Lin C-L G, Dykes-Hoberg M, Rothstein JD (1997) Cellular and synaptic localization of the neuronal glutamate transporters EAAT3 and EAAT4. Neuroscience, in press.

Ginsberg SD, Martin LJ, Rothstein JD (1995) Regional deafferentation down-regulates subtypes of glutamate transporter proteins. J Neurochem 65:2800-2803.

Gordon KE, Simpson J, Statman D, Silverstein FS (1991) Effects of perinatal stroke on striatal amino acid efflux in rat studied with in vivo microdialysis. Stroke 22:928-932.

Hagberg H, Andersson P, Kjellmer I, Thiringer K, Thordstein M (1987) Extracellular overflow of glutamate, aspartate, GABA and taurine in the cortex and basal ganglia of fetal lambs during hypoxia-ischemia. Neurosci Lett 78:311-317.

Haugeto $\varnothing$, Ullensvang K, Levy LM, Chaudhry FA, Honoré T, Nielsen M, Lehre KP, Danbolt NC (1996) Brain glutamate transporter proteins form homomultimers. J Biol Chem 271:27715-27722.

Herrmann K (1996) Differential distribution of AMPA receptors and glutamate during pre- and postnatal development in the visual cortex of ferrets. J Comp Neurol 375:1-17.

Jacobson M (1991) Developmental neurobiology. New York: Plenum.
Kanai Y, Hediger M (1992) Primary structure and functional characterization of a high affinity glutamate transporter. Nature 360:467-471.

Kanai Y, Smith CP, Hediger MA (1993) A new family of neurotransmitter transporters: the high-affinity glutamate transporters. FASEB J. 7:1450-1459.

Kanai Y, Nussberger S, Romero MF, Boron WF, Hebert SC, Hediger MA (1995) Electrogenic properties of the epithelial and neuronal high-affinity glutamate transporter. J Biol Chem 270:16561-16568.

Lauder JM (1993) Neurotransmitters as growth regulatory signals: role of receptors and second messengers. Trends Neurosci 16:233-240.

Lehre KP, Levy LM, Ottersen OP, Storm-Mathisen J, Danbolt NC (1995) Differential expression of two glutamate transporters in rat brain: quantitative and immunocytochemical observations. J Neurosci 15:1835-1853.

LoTurco JJ, Owens DF, Heath MJS, Davis MBE, Kriegstein AR (1995) GABA and glutamate depolarize cortical progenitor cells and inhibit DNA synthesis. Neuron 15:1287-1298.

MacDonald JW, Johnston MV (1990) Physiological and pathophysiological roles and excitatory amino acids during central nervous system development. Brain Res Rev 15:41-70.

Marín-Padilla M (1992) Ontogenesis of the pyramidal cell of the mammalian neocortex and developmental cytoarchitectonics: a unifying theory. J Comp Neurol 321:223-240.

Martin LJ, Brambrink AM, Lehmann C, Portera-Cailliau C, Koehler R, Rothstein J, Traystman RJ (1997a) Hypoxia-ischemia causes abnormalities in glutamate transporters and death of astroglia and neurons in newborn striatum. Ann Neurol 42:335-348.

Martin LJ, Furuta A, Blackstone CD (1997b) AMPA receptor protein in developing rat brain: GluR1 expression and localization change at regional, cellular, and subcellular levels with maturation. Neuroscience in press.

Miller RH, David S, Patel R, Abney ER, Raff MC (1985) A quantitative immunohistochemical study of macroglial cell development in the rat optic nerve: in vivo evidence for two distinct astrocyte lineages. Dev Biol 111:35-41.

Mount HT, Dreyfus CF, Black IB (1993) Purkinje cell survival is differentially regulated by metabotropic and ionotropic excitatory amino acid receptors. J Neurosci 13:3173-3179.

Northington FJ, Traystman RJ, Koehler RC, Rothstein JD, Martin LJ (1997) Regional and cellular expression of GLT1 and EAAC1 glutamate transporter proteins in ovine fetal brain. Neuroscience, in press.

Oka A, Belliveau MJ, Rosenberg PA, Volpe JJ (1993) Vulnerability of oligodendroglia to glutamate: pharmacology, mechanism, and prevention. J Neurosci 13:1441-1453.

Patel AP (1997) Neurotransmitter transporter proteins. Posttranslational modifications. In: Neurotransmitter transporters: structure, function, and regulation (Reith MEA, ed), pp 241-262. Totowa, NJ: Humana.

Patel AP, Cerruti C, Vaughan RA, Kuhar MJ (1994) Developmentally regulated glycosylation of dopamine transporter. Dev Brain Res 83:53-58.

Pines G, Danbolt NC, Bjørås M, Zhang Y, Bendahan A, Eide L, Koepsell H, Storm-Mathisen J, Seeberg E, Kanner BI (1992) Cloning and expression of a rat brain L-glutamate transporter. Nature 360:464-467.

Rosenberg PA, Amin S, Leitner M (1992) Glutamate uptake disguises neurotoxic potency of glutamate agonists in cerebral cortex in dissociated cell culture. J Neurosci 12:56-61.

Rothstein JD, Martin LJ, Kuncl RW (1992) Decreased brain and spinal cord glutamate transport in amyotrophic lateral sclerosis. N Engl J Med 326:1464-1468.

Rothstein JD, Martin L, Levey AI, Dykes-Hoberg M, Jin L, Wu D, Nash N, Kuncl RW (1994) Localization of neuronal and glial glutamate transporters. Neuron 13:713-725.

Rothstein JD, van Kammen M, Levey AI, Martin LJ, Kuncl RW (1995) Selective loss of glial glutamate transporter GLT-1 in amyotrophic lateral sclerosis. Ann Neurol 38:73-84.

Rothstein JD, Dykes-Hoberg M, Pardo CA, Bristol LA, Jin L, Kuncl RW, Kanai Y, Hediger MA, Wang Y, Schielke JP, Welty DF (1996) Knockout of glutamate transporters reveals a major role for astroglial transport in excitotoxicity and clearance of glutamate. Neuron 16:675-686.

Schmitt A, Asan E, Püschel B, Jöns T, Kugler P (1996) Expression of the glutamate transporter GLT1 in neural cells of the rat central nervous system: non-radioactive in situ hybridization and comparative immunocytochemistry. Neuroscience 71:989-1004. 
Shibata T, Watanabe M, Tanaka K, Wada K, Inoue Y (1996) Dynamic changes in expression of glutamate transporter mRNAs in developing brain. NeuroReport 7:705-709.

Silverstein FS, Buchanan K, Johnston MV (1986) Perinatal hypoxiaischemia disrupts striatal high-affinity ${ }^{3} \mathrm{H}$-glutamate uptake into synaptosomes. J Neurochem 47:1614-1619.

Storck T, Schulte S, Hofmann K, Stoffel W (1992) Structure, expression, and functional analysis of a $\mathrm{Na}^{+}$-dependent glutamate/aspartate transporter from rat brain. Proc Natl Acad Sci USA 89:10955-10959.

Sutherland ML, Delaney TA, Noebels JL (1996) Glutamate transporter mRNA expression in proliferative zones of the developing and adult murine CNS. J Neurosci 16:2191-2207.
Swanson RA, Liu J, Miller JW, Rothstein JD, Farrell K, Stein BA, Longuemare MC (1997) Neuronal regulation of glutamate transporter subtype expression in astrocytes. J Neurosci 17:932-940.

Szatkowski M, Attwell D (1994) Triggering and execution of neuronal death in brain ischaemia: two phases of glutamate release by different mechanisms. Trends Neurosci 17:359-365.

Torp R, Danbolt NC, Babaie E, Bjørås M, Seeberg E, Storm-Mathisen J, Ottersen OP (1994) Differential expression of two glial glutamate transporters in the rat brain: an in situ hybridization study. Eur J Neurosci 6:936-942.

Yamada K, Watanabe M, Shibata T, Tanaka K, Wada K, Inoue Y (1996) EAAT4 is a post-synaptic glutamate transporter at Purkinje cell synapses. NeuroReport 7:2013-2017. 